\title{
PENGETAHUAN, SIKAP DAN KESIAPAN MAHASISWA PROGRAM PROFESI NERS DALAM PENERAPAN EVIDENCE BASED PRACTICE
}

\author{
Hasniatisari Harun $^{1 *}$, Yusshy Kurnia Herliani ${ }^{1}$, Anita Setyawati ${ }^{2}$ \\ ${ }^{1}$ Keperawatan Medikal Bedah, Fakultas Keperawatan Universitas Padjadjaran \\ ${ }^{2}$ Keperawatan Maternitas, Fakultas Keperawatan Universitas Padjadjaran \\ *hasniatisari.harun@unpad.ac.id
}

\begin{abstract}
Abstrak
Kebutuhan perawat profesional dapat dicapai melalui program profesi ners yang merupakan bagian dari program pendidikan keperawatan, dimana didalamnya terjadi proses pembelajaran klinik untuk menciptakan perawat profesional yang kompeten. Salah satu peran perawat professional adalah terus mengupdate keilmuan dengan cara menelaah jurnal terbaru untuk mengekplorasi intervensi keperawatan terbaik bagi pasien sehingga mendapat hasil yang optimal. Mahasiswa program profesi ners pada saat jenjang pendidikan perkuliahan telah terlatih untuk menelaah kasus dengan menggunakan metode EBP, namun belum terdapat evaluasi terkait pemahaman mahasiswa terhadap metode tersebut serta penerapannya pada tatanan praktik klinik. Dengan demikian, penelitian ini bertujuan untuk mengidentifikasi bagaimana pengetahuan, sikap dan kesiapan mahasiswa dalam penerapan evidence based practice ada pasien kelolaan di stase keperawatan medikal bedah. Penelitian ini adalah penelitian kuantitatif. Sampel pada penelitian ini adalah mahasiswa program profesi ners yang sedang menjalankan praktik klinik dengan menggunakan teknik pengambilan sampel total sampling, yaitu sebanyak 120 responden. Instrumen yang digunakan adalah kuesioner Evidence Based Practice Questionnaire dengan menggunakan analisis deskriptif berupa distribusi frekuensi. Hasil penelitian menunjukan bahwa pengetahuan mahasiswa pada konsep Evidence based practice adalah baik sebanyak $68 \%$, sebagian besar responden memiliki sikap yang positif sebesar $85 \%$ dan lebih dari setengah responden mempunyai kesiapan yang cukup sebanyak 59\%. Temuan hasil penelitian ini adalah penting untuk rekomendasi masukan terkait mengembangkan bahan ajar pada lingkup pendidikan keperawatan terkait praktik keperawatan dalam memberikan pelayanan terbaik untuk pasien
\end{abstract}

Kata kunci : evidance based practice; pengetahuan; sikap; kesiapan

\begin{abstract}
Knowledge, attitude and readiness of students ners profession program in the implementation of evidence based practice. Professional nurses in Indonesia are prepared through the clinical education program (Ners Program) which is part of the nursing educational program. Student in the Ners program learn to be competent professional nurses during their clinical practice. One of the roles of professional nurses is to keep updating the knowledge by reviewing the most up-to-date information. Therefore, professional nurse could explore the best nursing interventions for patients to provide optimal care. The students of Ners program of the Faculty of Nursing Unversitas Padjadjaran have been learned to analyze the case and solve the nursing problem using EBP analysis during bachelor nursing program. However, the understanding and implementation of the students related EBP especially in the clinical practice setting were not evaluated yet. This study aims to identify the knowledge, attitude and readiness of students in the implementation of evidence based practice (EBP) along providing care to the patient during medical surgical nursing stages. This research is quantitative research. 120 respondents who were recruited in this study were students of the Ners Program who were performing clinical practice. The instrument used was the Evidence Based Practice Questionnaire $(E B P Q)$. The results were analyzed using descriptive analysis (frequency, percentage, and mean). The results showed that the knowledge of students on the concept of Evidence based practice was good as much as $68 \%$, the majority of respondents had a positive attitude of $85 \%$ and more than half of respondents had sufficient readiness of 59\%. The findings of this study are important for input recommendations related to developing teaching materials in the scope of nursing education related to nursing practice in providing the best service for patients
\end{abstract}

Keywords: evidance based practice; knowledge; attitude; readiness 


\section{Pendahuluan}

Keperawatan merupakan bagian integral dari pelayanan kesehatan. Pelayanan kesehatan merupakan suatu bentuk pelayanan professional yang didasarkan pada ilmu keperawatan. Di Indonesia, perawat mempunyai proporsi terbesar $(75 \%)$ dibandingkan dengan tenaga kesehatan lainnya dan merupakan profesi yang lebih banyak berinteraksi dengan klien untuk dapat meningkatkan derajat kesehatan (Depkes RI, 2005). Sementara, di negara maju kebutuhan tenaga perawat melonjak dengan drastis dari tahun ke tahun dan diperkirakan akan mencapai 1 juta ditahun 2020 untuk mendukung kebutuhan pelayanan kesehatan.

Kebutuhan perawat profesional dapat dicapai melalui program profesi ners yang merupakan bagian dari program pendidikan keperawatan, dimana didalamnya terjadi proses pembelajaran klinik untuk menciptakan perawat profesional yang kompeten. (Dorothy E. Reilly, 1985). Program ini bertujuan untuk membangun sikap dan kemampuan mahasiswa program profesi ners menjadi perawat profesional dalam bentuk pengalaman belajar klinik dan lapangan secara komprehensif. Salah satu program klinik pendidikan profesi ners, yaitu praktik keperawatan medikal bedah yang mana fokus prakteknya mengembangkan kemampuan mahasiswa dalam telaah klinis dengan mengintegrasikan pemahaman berbagai konsep dasar asuhan keperawatan orang dewasa yang mengalami gangguan berbagai sistem tubuh. (Pedoman panduan program profesi ners keperawatan medikal bedah, 2016).

Praktik keperawatan medikal bedah mempunyai berbagai metode salah satunya mengaplikasikan evidence based practice (EBP). Evidence based practice merupakan suatu kerangka kerja yang menguji, mengevaluasi dan menerapkan temuan-temuan penelitian dengan tujuan untuk memperbaiki pelayanan keperawatan kepada pasien (Carlson, 2010). Penelitian terkait evidence based practice yang sudah dilakukan di Indonesia, Salah satunya oleh Ligita pada tahun 2012 terhadap 66 perawat rumah sakit umum di pontianak menunjukan hasil bahwa perawat tidak memiliki cukup persiapan dalam hal pengetahuan dan kebiasaan dalam melakukan penelitian serta membaca penelitian yang sangat penting dalam mendukung pelaksanaan implementasi.

Mahasiswa program profesi ners

Fakultas Keperawatan Universitas Padjadjaran pada saat jenjang pendidikan perkuliahan telah terlatih untuk menelaah kasus dengan menggunakan metode EBP, namun belum terdapat evaluasi terkait pemahaman mahasiswa terhadap metode tersebut serta penerapannya pada tatanan praktik klinik. Oleh sebab itu, mahasiswa profesi ners perlu dikaji lebih lanjut terkait kompetensi penerapan EBP pada pasien kelolaan di stase keperawatan medikal bedah sebelum menempuh praktik klinik. Selain itu, belum terdapat penelitian sebelumnya terkait kompetensi mahasiswa profesi ners dalam mengimplementasikan EBP terhadap kasus kelolaan pada tatanan klinik.

Pada tahun 2012, Hasil penelitian dari Ligita mendukung fenomena tersebut dengan mengemukakan bahwa dalam jenjang pendidikan keperawatan sudah seharusnya diperkenalkan sedini mungkin konsep EBP sehingga mahasiswamahasiswa lulusan perguruan tinggi tidak hanya paham akan teori dan praktik keperawatan akan tetapi juga memahami pentingnya hasil penelitian dalam menentukan hasil perawatan terbaik pada pasien. (Yadav \& Fealy, 2012). Berdasarkan uraian tersebut diperlukan penelitian yang bertujuan untuk mengeksplorasi bagaimana pengetahuan, sikap dan kesiapan mahasiswa program profesi ners dalam penerapan EBP terhadap pasien kelolaan pada stase keperawatan medikal bedah di Fakultas Keperawatan Universitas Padjadjaran. Penelitian ini merupakan penelitian kuantitatif. 


\section{Metode}

Penelitian deskriptif eksploratif dengan menggunakan metode kuantitatif. Populasi dalam penelitian ini mahasiswa program profesi ners yang telah menjalani program profesi pada stase keperawatan medikal bedah Fakultas Keperawatan Universitas Padjadjaran. Pengambilan Sampel yang digunakan dalam penelitian ini diambil secara total sampling selama masa pengumpulan data selama satu bulan di tatanan klinik. Sampel yang menjadi fokus dalam penelitian ini adalah mahasiswa program profesi ners yang telah menjalani program profesi tanpa dilakukan seleksi berdasarkan kriteria inklusi dan eksklusi (Total sampling). Berdasarkan data saat pengumpulan data yang berkontribusi dalam penelitian ini sebanyak 120 mahasiswa.

Instrumen yang digunakan adalah kuesioner Evidence Based Practice Questionnaire (EBPQ) milik Upton (2006).
Instrumen ini untuk menilai pengetahuan, sikap dan kesiapan dalam penerapan Evidence based practice. EBPQ terdiri dari 7 titik skala penilaian. Data analisis dengan menggunakan analisa dektriptif terdiri dari frekuensi, persentase dan rata-rata untuk mengedentifikasi gambaran pengetahuan, sikap dan kesiapan. Penelitian ini telah mendapatkan persetujuan etik oleh Komisi Etik Penelitian Kesehatan Fakultas Kedokteran Universitas Padjadjaran dengan nomor 861/UN6.C.10/PN/2017.

\section{Hasil}

Untuk mengetahui pengetahuan mahasiswa program profesi ners dalam penerapan Evidence-based Practice terhadap pasien kelolaan dilakukan dengan cara memberikan jawaban pada kuesioner yang telah diberikan kepada responden, yang hasilnya ditampilkan pada table dibawah ini.

Tabel 1.

Gambaran pengetahuan mahasiswa program profesi ners dalam penerapan Evidencebased Practice terhadap pasien kelolaan $(n=120)$

\begin{tabular}{clccc}
\hline Variabel & & Kategori & $\mathrm{f}$ & $\%$ \\
\hline Pengetahuan & Baik & 82 & 68 \\
& Kurang & 38 & 32 \\
\hline
\end{tabular}

Bedasarkan tabel 1 di atas menunjukan bahwa gambaran pengetahuan mahasiswa program profesi ners dalam penerapan Evidence-based Practice terhadap pasien kelolaan, sebagian besar dari responden yang mempunyai pengetahuan baik $(68 \%)$. Untuk mengetahui sikap mahasiswa program profesi ners dalam penerapan Evidencebased Practice terhadap pasien kelolaan dilakukan dengan cara memberikan jawaban pada kuesioner yang telah diberikan kepada responden, yang hasilnya ditampilkan pada table dibawah ini.

Tabel 2.

Gambaran sikap mahasiswa program profesi ners dalam penerapan Evidence-based Practice terhadap pasien kelolaan $(\mathrm{n}=120)$

\begin{tabular}{llcl}
\hline Variabel & Kategori & $\mathrm{f}$ & $\%$ \\
\hline \multirow{2}{*}{ Sikap } & Mendukung & 103 & 85 \\
& Tidak Mendukung & 17 & 15 \\
\hline
\end{tabular}

Bedasarkan tabel 2 di atas menunjukan Untuk mengetahui kesiapan mahasiswa bahwa gambaran sikap mahasiswa program profesi ners dalam penerapan program profesi ners dalam penerapan Evidence-based Practice terhadap pasien Evidence-based Practice terhadap pasien kelolaan dilakukan dengan cara kelolaan, mayoritas dari responden yang memberikan jawaban pada kuesioner yang mempunyai sikap mendukung $(85 \%)$. telah diberikan kepada responden, yang 
hasilnya ditampilkan pada table dibawah ini.

Tabel 3.

Gambaran kesiapan mahasiswa program profesi ners dalam penerapan Evidence-based Practice terhadap pasien kelolaan $(n=120)$

\begin{tabular}{|c|c|c|c|}
\hline \multirow{2}{*}{$\begin{array}{ll} & \text { Variabel } \\
\text { Kesiapan }\end{array}$} & Kategori & $f$ & $\%$ \\
\hline & Baik & 71 & 60 \\
\hline & Kurang Baik & 49 & 40 \\
\hline
\end{tabular}

Bedasarkan tabel 2 di atas menunjukan bahwa gambaran kesiapan mahasiswa program profesi ners dalam penerapan Evidence-based Practice terhadap pasien kelolaan, sebagian besar dari responden yang mempunyai sikap baik $(60 \%)$.

\section{Pembahasan}

Evidence based practice (EBP) didefinisikan sebagai suatu kerangka kerja yang menguji, mengevaluasi dan mengaplikasikan temuan-temuan penelitian dengan tujuan untuk memperbaiki pelayanan keperawatan kepada pasien (Carlson, 2010). Evidencebased practice menjadi suatu pola kerja dimana bukti ilmiah terbaik yang didapat melalui penelitian, pengalaman klinik perawat serta pilihan pasien dalam menentukan keputusan klinik bagi pelayanan kesehatan menjadi landasan dalam pemberian asuhan keperawatan (Carlson, 2010; Levin \& Feldman, 2006).

Hasil penelitian ini menunjukan lebih dari setengah responden sebanyak $68 \%$ mempunyai pengetahuan yang baik terkait penerapan evidence based practice. Pemahaman terkait konsep Evidence-based Practice sangat diperlukan untuk dapat mengembangkan dan mengaplikasikan model Evidence-based Practice dengan tepat. Pengetahuan mahasiswa dalam penelitian ini mencakup 7 komponen terdiri atas pengertian evidence based practice, tujuan, bentuk Evidence-based Practice, keterampilan yang diperlukan dalam Evidence-based Practice, jenis penelitian yang mendukung terbentuknya Evidence-based Practice serta sumber elektronik (website) yang dapat digunakan untuk mencarai bukti (evidence) terbaik.
Pengetahuan merupakan hal vital di dalam mengimplementasikan evidencebased practice. Pengetahuan yang dimilki tidak semata-mata terdiri dari konsep saja, akan tetapi diperlukan pengetahuan mengenai cara melaksanakan Evidencebased Practice. Hal ini diperkuat oleh argumentasi (Munroe, Duffy, \& Fisher, 2008) bahwa pengetahuan perawat klinis akan cara menerapkan evidence-based practice pun adalah hal yang berpengaruh kuat pada keberhasilan implementasi Evidence based.

Selain pengetahuan, dalam penelitian ini juga melihat sikap mahasiswa program profesi ners dalam penerapan Evidence-based Practice. Penerapan evidence-based practice akan terlaksana dengan baik bila mahasiswa memiki sikap yang positif terhadap evidence-based practice. Pengetahuan dan pengalaman yang memadai juga harus didukung sikap yang positif (Holleman, Eliens, Van Vliet, \& Van Achterber, 2006, dalam Ligita, 2014). Beberapa penelitian menunjukkan bahwa sikap positif perawat terhadap evidence-based practice relevan dengan penerapan evidence-based practice.

Penelitian - penelitian sebelumnya mengenai sikap perawat tentang evidencebased practice menunjukkan hasil yang berbeda - beda. Beberapa hasil penelitian menunjukkan bahwa perawat menyikapi evidence-based practice secara positif dan setuju bahwa penelitian dan evidencebased practice relevan dengan praktek harian mereka (Nagy et al. 2001, SanzeroEller et al. 2003, Wallin et al. 2003, Milner et al. 2006, dalam Eizenberg, 2011). Sementara beberapa hasil penelitian lainnya menunjukkan bahwa perawat menyikapi penelitian secara negatif dan 
merupakan yang terendah dibanding tenaga kesehatan lainnya (Nagy et al. 2001, Sanzero-Eller et al. 2003, dalam Eizenberg, 2011). Hasil penelitian yang dilakukan oleh Pravikoff et al. (2005, dalam Williams, 2013) menunjukkan bahwa meski perawat menyadari pentingnya evidence-based practice, mereka lebih memilih berdiskusi dengan rekan sejawat dibandingkan membaca hasil penelitian

Kesiapan keterampiran dalam implementasi konsep Evidence-based Practice juga sangat dibutuhkan. Dalam penelitian ini kesiapan mahasiswa dalam menerapkan evidence based practice adalah sebanyak $71 \%$ dalam kategori baik. Keterampilan yang dimaksud adalah mencari hasil-hasil penelitian, mengevaluasi hasil penelitian dan mengaplikasikannya (Hart et al., 2008). Hasil penelitian dapat diidentifikasi baik secara online maupun melalui majalahmajalah ilmiah (jurnal) yang tersedia. Untuk itu kebiasaan dalam menggunakan fasilitas komputer sangat diperlukan terutama bila mencari artikel pada jurnal secara online. Apabila perawat tidak terlatih dalam mencari informasi secara online, mereka cenderung enggan untuk menggunakan website (Thompson, McCaughan, Cullum, Sheldon, \& Raynor, 2003). Selanjutnya adalah terampil dalam mengevaluasi hasil penelitian sehingga perawat dapat menentukan pilihan asuhan yang terbaik untuk pasiennya dari temuantemuan tersebut.

\section{Simpulan}

Adanya mata kuliah khusus terkait penerapan evidence based practice dalam pendidikan jenjang sarjana. Mata kuliah tersebut harus dirancang dengan baik dan berfokus pada praktik Evidence based practice pada pengelolaan kasus kasus yang sering muncul di lapangan, hal tersebut merupakan pendekatan potensial untuk meningkatkan pengetahuan dan memfasilitasi pelaksanaan EBP. Sehingga mahasiswa nantinya dapat melakukan praktik berbasis bukti (EBP) untuk mengekplorasi intervensi keperawatan terbaik bagi pasien sehingga mendapat hasil yang optimal.

\section{Daftar Pustaka}

Aglen, B. (2016). Pedagogical strategies to teach bachelor students evidencebased practice: A systematic review. Nurse education today, 36(Supplement C), 255-263. doi: https://doi.org/10.1016/j.nedt.2015.0 $\underline{8.025}$

Azmoude, E., Farkhondeh, F., Ahour, M., \& Kabirian, M. (2017). Knowledge, Practice and Self-Efficacy in Evidence-Based Practice among Midwives in East Iran. Sultan Qaboos Univ Med J, 17(1), e66-e73. doi: 10.18295/squmj.2016.17.01.012

Bloom, K. C., Olinzock, B. J., Radjenovic, D., \& Trice, L. B. (2013). Leveling EBP content for undergraduate nursing students. Journal of Professional Nursing, 29(4), 217224.

Depkes RI. (2016). Situasi Tenaga Keperawatan Indonesia. Pusat data dan Informasi Kementerian Kesehatan RI. ISSN 2442-7659

Elysabeth, D., Libranty, G., \& Natalia, S. (2015). Hubungan Tingkat Pendidikan Perawat Dengan Kompetensi Aplikasi EvidenceBased Practice Correlation Between Nurse's Education Level With The Competency To Do Evidence-Based Practice. Jurnal Skolastik Keperawatan, 1(01).

Farokhzadian, J., Khajouei, R., \& Ahmadian, L. (2015). Evaluating factors associated with implementing evidence-based practice in nursing. Journal of evaluation in clinical practice, 21(6), 1107-1113. 
Häggman-Laitila, A., Mattila, L.-R., \& Melender, H.-L. (2016). Educational interventions on evidence-based nursing in clinical practice: a systematic review with qualitative analysis. Nurse education today, 43, 50-59.

Hande, K., Williams, C. T., Robbins, H. M., Kennedy, B. B., \& Christenbery, T. (2017). Leveling Evidence-based Practice Across the Nursing Curriculum. The Journal for Nurse Practitioners, 13(1), e17-e22.

Ligita, T. (2012). Pengetahuan, Sikap dan Kesiapan Perawat Klinisi dalam Implementasi Evidence Based Practice. Ners Jurnal Keperawatan 8(1) 83-95

Mashiach Eizenberg, M. (2011). Implementation of evidence-based nursing practice: nurses' personal and professional factors? Journal of advanced nursing, 67(1), 33-42.

Masters, K. (2015). Role development in professional nursing practice: Jones $\&$ Bartlett Publishers.

Melnyk, B. M., Gallagher-Ford, L., Long, L. E., \& Fineout-Overholt, E. (2014). The establishment of evidence-based practice competencies for practicing registered nurses and advanced practice nurses in real-world clinical settings: proficiencies to improve healthcare quality, reliability, patient outcomes, and costs. Worldviews on Evidence-Based Nursing, 11(1), 515.

Mohsen, M. M., Safaan, N. A., \& Okby, O. M. (2016). Nurses' perceptions and barriers for adoption of evidence based practice in primary care:
Bridging the gap. American Journal of Nursing Research, 4(2), 25-33.

Munroe, D., Duffy, P., \& Fisher, C. (2008). Nurse knowledge, skills, and attitudes related to evidencebased practice: Before and after organizational supports. Medical Surgical Nursing, 17(1), 55-60.

Oh, E. G., Yang, Y. L., Sung, J. H., Park, C. G., \& Chang, A. M. (2016). Psychometric Properties of Korean Version of Self-Efficacy of Evidence-Based Practice Scale. Asian nursing research, 10(3), 207212.

Pedoman panduan program profesi ners keperawatan medikal bedah Fakultas Keperawatan Universitas Padjadjaran, 2016

Standar kompetensi perawat Indonesia. Bidang Organisasi PP-PPNI: Jakarta.

Upton, D., \& Upton, P. (2006). Development of an evidence-based practice questionnaire for nurses. $J$ Adv Nurs, 53(4), 454-458. doi: 10.1111/j.1365-2648.2006.03739. 